\title{
Effect of folylpolyglutamate synthase A22G polymorphism on the risk and survival of patients with acute lymphoblastic leukemia
}

\author{
YAZMÍN GÓMEZ-GÓMEZ ${ }^{1,5^{*}}$, JORGE ORGANISTA-NAVA ${ }^{1 *}$, CARLOS ALBERTO RANGEL-RODRIGUEZ $^{2}$, \\ BERENICE ILLADES-AGUIAR ${ }^{2}$, MARÍA ELENA MORENO-GODÍNEZ ${ }^{3}$, \\ LUZ DEL CARMEN ALARCÓN-ROMERO ${ }^{4}$ and MARCO ANTONIO LEYVA-VÁZQUEZ ${ }^{* *}$ \\ ${ }^{1}$ Institute of Cellular Physiology, National Autonomous University of Mexico (UNAM), Mexico City 04510; \\ Laboratories of ${ }^{2}$ Molecular Biomedicine, ${ }^{3}$ Toxicology and Environmental Health and ${ }^{4}$ Cytopathology, \\ School of Biological Sciences, Guerrero State University, Chilpancingo, Guerrero 39090, Mexico
}

Received September 12, 2013; Accepted March 27, 2014

DOI: 10.3892/ol.2014.2175

\begin{abstract}
Folylpolyglutamate synthase (FPGS) is the key enzyme that converts the chemotherapeutic agent, methotrexate (MTX), into MTX polyglutamate. An A22G polymorphism has been found in the FPGS gene. This study aimed to evaluated whether the $\mathrm{A} 22 \mathrm{G}$ polymorphism in the FPGS gene is associated with an increased risk of acute lymphoblastic leukemia (ALL) and whether it plays a role in increasing the survival of patients with ALL. In this study, a total of 70 patients with ALL and 100 healthy individuals were genotyped by polymerase chain reaction and sequencing methods. The homozygous variant, 22G/G [odds ratio $(\mathrm{OR})=3.88$; $95 \%$ confidence interval $(\mathrm{CI}): 2.50-6.03$ ] and the heterozygous variant, $22 \mathrm{~A} / \mathrm{G}(\mathrm{OR}=1.37 ; 95 \% \mathrm{CI}: 1.26-48.95)$ were risk factors for ALL. Patients with the 22A/G genotype had an OR of 1.81 (95\% CI: 1.57-5.74; $\mathrm{P}=0.049)$ and carriers of the 22G/G genotype had an OR of 2.44 (95\% CI: 2.40-11.82; $\mathrm{P}=0.017)$ for relapse. A significant association between the A22G polymorphism and survival of patients with ALL was found $(\mathrm{P}<0.05)$; whereas, individuals with $\mathrm{A} / \mathrm{G}$ or $\mathrm{G} / \mathrm{G}$ genotypes had a decreased overall survival (log-rank test, $\mathrm{P}=0.044$ ). Although preliminary, these data suggest that the genotypes of the $\mathrm{A} 22 \mathrm{G}$ polymorphism may be risk factors for ALL and may play a role in the survival of patients with ALL.
\end{abstract}

Correspondence to: Dr Marco Antonio Leyva-Vázquez, Laboratory of Molecular Biomedicine, School of Biological Sciences, Guerrero State University, Av. Lázaro Cárdenas S/N, Ciudad Universitaria, Chilpancingo, Guerrero 39090, Mexico

E-mail: leyvamarco13@gmail.com

Present address: ${ }^{5}$ State Cancer Institute 'Arturo Beltran Ortega', Av. Ruiz Cortines 128-A Col. Alta Progreso, Acapulco, Guerrero 39570, Mexico

${ }^{*}$ Contributed equally

Key words: acute lymphoblastic leukemia, folylpolyglutamate synthase, survival, $\mathrm{A} 22 \mathrm{G}$ polymorphism

\section{Introduction}

Acute leukemias (ALs) are the most frequent type of cancer occurring in children (1). In Mexico City, $85 \%$ of the cases were acute lymphoblastic leukemia (ALL) and $14.5 \%$ were acute myeloblastic leukemia, with a low percentage of acute biphenotypic or non-differentiated AL (1). From 1996 to 2000, a mortality rate of 63.7 per million children was recorded, which is one of the highest rates reported worldwide (2). In 2005 , leukemia was the second highest cause of mortality in Guerrero in children $<15$ years old (3). An antineoplastic agent commonly used for the treatment of ALL is methotrexate (MTX), which was introduced to clinical oncology 50 years ago. Folylpolyglutamate synthase (FPGS) catalyzes the polyglutamation of MTX to produce highly active metabolites (4). Certain polymorphisms at specific sites in the FPGS gene may decrease the affinity for its substrate, causing deficient polyglutamation of MTX (4). The A22G polymorphism (rs10760502), which replaces Ile with Val at position 22 of the FPGS protein, was identified in African-American, Caucasian-American, Chinese-American and Mexican-American populations (4); however, this polymorphism has not yet been studied as a factor for ALL. The present study retrospectively evaluated whether the A22G polymorphism in the FPGS gene is associated with an increased risk and survival for ALL.

\section{Materials and methods}

Study population. Patients $(n=70)$ with ALL at the Pediatric Oncology Service of the State Cancer Institute 'Arturo Beltran Ortega' (Acapulco, Guerrero) who were diagnosed between August, 2005 and August, 2010 via bone marrow aspiration based on the French-American-British morphological criteria, cytochemical staining properties and subclassified as T- or B-lineages as previously described (5), were included in the present study. Multiagent chemotherapeutic protocols used were 96091, 96092 or CIE-10:C9.1.0 of the State Cancer Institute 'Arturo Beltran Ortega', as previously described $(5,6)$. This study and the informed consent protocol were approved by the institutional review board of the Cancer Institute. Complete remission, relapse and poor outcomes were as previously 
defined (5,7). Risk classification was as follows: Low risk, individuals aged between one and nine years old presenting with a white blood cell (WBC) count of $<50,000 / \mathrm{mm}^{3}$; and high risk, individuals aged less than one or more than nine years old with a WBC count of $>50,000 / \mathrm{mm}^{3}(5,7)$. The controls included 100 healthy individuals $\left(4-10 \times 10^{3}\right.$ leukocytes $\left./ \mathrm{mm}^{3}\right)$ without a family history of leukemia. Collectively, the subjects in the two groups were between one and 18 years old, included males and females, and were residents of Guerrero, Mexico. Patients provided written informed consent.

Specimen collection. A bone marrow and/or blood sample was collected from the 170 participants and placed in tubes with anticoagulant. Leukocytes were purified from the whole blood sample by a selective osmotic lysis of erythrocytes; the leukocyte genomic DNA was extracted using the phenol-chloroform technique, as described previously (8).

Genotyping. The A22G polymorphism (rs10760502) was detected by polymerase chain reaction (PCR) and sequencing using forward (5'-ACCTGCGCGCCGCTCTATTC-3') and reverse (5'-GCTGGCCCGCCTGATACCTG-3') primers, according to previously established protocols (9). The PCR products were sequenced using the ABI PRISM 310 Genetic analyzer (PE Applied Biosystems, Foster City, CA, USA) and sequence data were analyzed using SeqManII software (DNASTAR, Inc., Madison, WI, USA) (Fig. 1).

Statistical analysis. Continuous data are presented as the means \pm standard deviation. Categorical data were compared by the $\chi^{2}$ or Fisher's exact tests. Univariate logistic regression analysis for the association between the risk of relapse and A22G genetic polymorphism, gender and other clinical characteristics were tested, and those factors that were significant in the univariate analysis were included in a second multivariate logistic analysis. The log-rank test and Kaplan-Meier curves were used to analyze the effects of the A22G genetic polymorphism and relapse of ALL on overall survival (OS). OS was defined as the time elapsed between the date of initial diagnosis and either death or the time of the last follow-up. The Hardy-Weinberg equilibrium (HWE) was used to determine the genetic equilibrium in the healthy group. $\mathrm{P}<0.05$ was considered to indicate a statistically significant difference. All the statistical analyses were performed using SPSS software, version 21.0 (SPSS, Inc., Chicago, IL, USA) and STATA software, version 9.2 (StataCorp, College Station, TX, USA).

\section{Results}

Clinical characteristics. The clinical characteristics of the study population have been previously reported $(5,7)$. Briefly, the 70 patients with ALL were aged between 1.0 and 18 years (mean age $\pm \mathrm{SD}, 7.65 \pm 4.67$ years), including $45(64.29 \%)$ males and $25(35.71 \%)$ females. Of these, 18 patients $(25.71 \%)$ were aged between one and nine years old, and 52 patients $(72.29 \%)$ were aged less than one year or more than nine years at the time of initial diagnosis. The median follow-up time was 38 months and the longest follow-up was six years, which occurred in only two patients. The relapse rate of patients with ALL was $68.57 \%$.
The control group included 100 healthy individuals aged between 1.0 and 18 years old (mean $\pm \mathrm{SD}, 9.99 \pm 5.49$ years) with a normal leukocyte count $\left(4-10 \times 10^{3}\right.$ leukocytes $/ \mathrm{mm}^{3}$; median 8,000 leukocytes $/ \mathrm{mm}^{3}$ ). In this group, 53 healthy individuals $(53 \%)$ were male and $47(47 \%)$ were female.

Association of $A 22 G$ polymorphism in FPGS with the risk of $A L L$. The genotype distribution and allele frequency of $\mathrm{A} 22 \mathrm{G}$ polymorphism in 70 patients with ALL and 100 healthy individuals were determined. As shown in Table I, the genotype distribution of $\mathrm{A} 22 \mathrm{G}$ polymorphism supported that expected by the HWE in healthy individuals. When the genotype frequencies were compared between the cases and controls, a statistically significant association with ALL was found $(\mathrm{P}<0.05)$. The homozygous variant, $\mathrm{G} / \mathrm{G}$ [odds ratio $(\mathrm{OR})=3.88$; 95\% confidence interval (CI): 2.50-6.03] and the heterozygote variant, $\mathrm{A} / \mathrm{G}(\mathrm{OR}=1.37$; $95 \% \mathrm{CI}$ : 1.26-48.95) were risk factors for ALL (Table I).

Risk of relapse based on genotypes and other clinical characteristics. A logistic regression analysis showed that those individuals with the genotype $22 \mathrm{~A} / \mathrm{G}$ were 1.78 -fold $(95 \%$ CI: $1.56-5.63 ; \mathrm{P}=0.323$ ) more likely to relapse during treatment, while individuals with genotype $22 \mathrm{G} / \mathrm{G}$ were 2.42 -fold $(95 \%$ CI: $1.99-11.76 ; \mathrm{P}=0.272$ ) more likely to relapse compared with individuals with genotype 22A/A (Table II). Individuals aged less than one or $>10$ years old with $>50,000$ leukocytes $/ \mathrm{mm}^{3}$ (high risk) were 1.68-fold (95\% CI: 1.36-3.72; $\mathrm{P}=0.05$ ) more likely to have relapsed compared with individuals aged between two and nine years old with $<50,000$ leukocytes $/ \mathrm{mm}^{3}$ (low risk) (Table II).

The following variables were included in the multivariate analysis: Number of leukocytes at diagnosis, age and A22G polymorphism genotypes, in order to determine whether the A $22 \mathrm{G}$ polymorphism genotypes predicted the risk of relapse independently. Patients with the genotype $22 \mathrm{~A} / \mathrm{G}$ or $22 \mathrm{G} / \mathrm{G}$ (OR=1.81; 95\% CI: 1.57-5.74; $\mathrm{P}=0.049$ and $\mathrm{OR}=2.4 ; 95 \%$ CI: $2.40-11.82 ; \mathrm{P}=0.017$, respectively), were two independent prognostic markers for the risk of relapse compared with the other variables (Table II).

Association between A22G polymorphism and survival of patients with ALL. The Kaplan-Meier survival curves showed no significant association between the FPGS A22G polymorphism and survival, although a reduction in survival after six years of follow-up among $\mathrm{A} / \mathrm{G}$ and $\mathrm{G} / \mathrm{G}$ carriers compared with the wild-type genotype was observed (log-rank test; $\mathrm{P}=0.078$ ) (Fig. 2A). However, a log-rank test for the combined genotypes, 22A/G + 22G/G vs. A/A (Fig. 2B), showed a significant association between the genotype-dependent effects for the survival of patients with ALL (log-rank test; $\mathrm{P}=0.044)$ and increased survival was observed in those patients with genotype 22A/A (Fig. 2).

\section{Discussion}

Agents that target the folate pathway, such as MTX, are an effective treatment for several hematologic malignancies and solid tumors. MTX is a structural analogue of folic acid that inhibits multiple enzymes in the folate pathway and requires 
Table I. Genotype distribution and allele frequency of the A22G polymorphism in the FPGS gene, and association with the risk of ALL.

\begin{tabular}{|c|c|c|c|c|c|c|c|}
\hline $\begin{array}{l}\text { A22G polymorphism } \\
\text { (rs10760502) }\end{array}$ & $\begin{array}{l}\text { ALL cases } \\
(\%)(\mathrm{n}=70)\end{array}$ & $\begin{array}{l}\text { Controls }(\%) \\
\quad(n=100)\end{array}$ & P-value & OR & $95 \% \mathrm{CI}$ & P-value & $\begin{array}{l}\text { P-value } \\
\text { HWE }\end{array}$ \\
\hline \multicolumn{8}{|l|}{ Genotypes } \\
\hline $\mathrm{A} / \mathrm{A}$ & $19(27.14)$ & $66(66.00)$ & \multirow[t]{3}{*}{$<0.001^{\mathrm{a}}$} & 1.00 & & & \multirow[t]{5}{*}{$0.086^{c}$} \\
\hline $\mathrm{A} / \mathrm{G}$ & $38(54.29)$ & $27(27.00)$ & & 1.37 & $1.26-48.95$ & $<0.001^{\mathrm{b}}$ & \\
\hline $\mathrm{G} / \mathrm{G}$ & 13 (18.57) & $7(7.00)$ & & 3.88 & $2.50-6.03$ & $<0.001^{\mathrm{b}}$ & \\
\hline $\mathrm{A} / \mathrm{A}$ & $19(27.14)$ & $66(66.00)$ & \multirow[t]{2}{*}{$<0.001^{\mathrm{a}}$} & 1.00 & & & \\
\hline $\mathrm{A} / \mathrm{G}+\mathrm{G} / \mathrm{G}$ & $51(72.86)$ & $34(34.00)$ & & 5.21 & $2.67-10.18$ & $<0.001^{\mathrm{b}}$ & \\
\hline \multicolumn{8}{|l|}{ Alleles } \\
\hline $\mathrm{A}$ & $76(54.29)$ & $159(79.50)$ & \multirow[t]{2}{*}{$<0.001^{\mathrm{a}}$} & 1.00 & & & \\
\hline $\mathrm{G}$ & $64(45.71)$ & $41(20.50)$ & & 1.92 & $1.22-3.01$ & $0.004^{\mathrm{b}}$ & \\
\hline
\end{tabular}

${ }^{\mathrm{a}}$ Obtained by the $\chi^{2}$ test. ${ }^{\mathrm{b}}$ Regression analysis, taking reference to AA genotype; ${ }^{\mathrm{C}} \mathrm{HWE}$ to controls. FPGS, folylpolyglutamate synthase; ALL, acute lymphoblastic leukemia; OR, odds ratio; 95\% CI, 95\% confidence interval; HWE, Hardy-Weinberg equilibrium.

Table II. Association between A22G polymorphism in the FPGS gene and clinical characteristics with the risk of ALL recurrence.

\begin{tabular}{|c|c|c|c|c|c|c|c|}
\hline \multirow[b]{2}{*}{ Characteristics } & \multirow[b]{2}{*}{ ALL cases $(\%)$} & \multicolumn{3}{|c|}{ Univariate analysis } & \multicolumn{3}{|c|}{ Multivariate analysis } \\
\hline & & OR & $95 \% \mathrm{CI}$ & P-value ${ }^{a}$ & OR & $95 \% \mathrm{CI}$ & P-value ${ }^{c}$ \\
\hline \multicolumn{8}{|l|}{ Gender } \\
\hline Female & $25(35.71)$ & 1.00 & & & & & \\
\hline Male & $45(64.29)$ & 1.38 & $0.49-3.92$ & 0.540 & & & \\
\hline \multicolumn{8}{|l|}{ Risk at diagnosis } \\
\hline Low risk & $18(25.71)$ & 1.00 & & & & & \\
\hline High risk & $52(74.29)$ & 7.64 & $1.90-30.73$ & $0.004^{\mathrm{b}}$ & 1.68 & $1.36-3.72$ & $0.05^{\mathrm{b}}$ \\
\hline \multicolumn{8}{|c|}{ A22G genotypes (rs 10760502) } \\
\hline $\mathrm{A} / \mathrm{A}$ & $19(27.14)$ & 1.00 & & & & & \\
\hline $\mathrm{G} / \mathrm{A}$ & $38(54.29)$ & 1.78 & $1.56-5.63$ & 0.323 & 1.81 & $1.57-5.74$ & $0.049^{\mathrm{b}}$ \\
\hline $\mathrm{G} / \mathrm{G}$ & $13(18.57)$ & 2.42 & 1.99-11.76 & 0.272 & 2.44 & $2.40-11.82$ & $0.017^{\mathrm{b}}$ \\
\hline \multicolumn{8}{|c|}{$\begin{array}{l}\text { P-value obtained by logistic regression analysis, taking reference to AA genotype, female, aged between two and nine years old and }<50,000 \\
\text { leukocytes } / \mathrm{mm}^{3} \text { (low risk). 'Significant at } \mathrm{P}<0.05 .{ }^{\mathrm{P}} \mathrm{P}-\mathrm{value} \text { obtained by multivariate logistic regression analysis. FPGS, folylpolyglutamate } \\
\text { synthase; ALL, acute lymphoblastic leukemia; OR, odds ratio; } 95 \% \text { CI, } 95 \% \text { confidence interval; low risk at diagnosis, individuals aged } \\
\text { between one and nine years old with }<50,000 \text { leukocytes } / \mathrm{mm}^{3} \text {; high risk, individuals aged less than one and more than nine years old with } \\
>50,000 \text { leukocytes } / \mathrm{mm}^{3} \text {. }\end{array}$} \\
\hline
\end{tabular}

polyglutamation by FPGS for activation. Patients with ALL have different responses to the same therapy, such as MTX resistance and subsequent relapse of ALL (10).

Leil et al (4) reported that the A22G polymorphism present in the FPGS gene affected individuals of Mexican-American descent and other populations conferring resistance to MTX. Additionally, Wessels et al (11) reported a high frequency of $\mathrm{A} 22 \mathrm{G}$ polymorphism in patients with rheumatoid arthritis (11). Moreover, a number of studies have been conducted investigating the role of FPGS polymorphisms in cancer $(12,13)$. Our data suggests that the A22G polymorphism is significantly associated with the risk of ALL $(\mathrm{P}<0.05)$ (Table I). However, there have been no studies evaluating the association of the $\mathrm{A} 22 \mathrm{G}$ polymorphism with the risk of relapse and survival in patients with ALL in the literature to date.

In this study, patients with ALL predominantly showed the heterozygous A/G genotype (54.29\%) of the A22G polymorphism (Table I), which is similar to the findings in the study by Wessels et al (11) on patients with rheumatoid arthritis (49\%) (11); however, these results are in contrast to the findings of Leil et al (4), in African-American (15.00\%), Caucasian-American (37.50\%), Han Chinese-American (3.30\%) and Mexican-American (32.50\%) populations (4). These data suggest that the $\mathrm{A} 22 \mathrm{G}$ polymorphism is found more frequently in patients with enzymatic activity of FPGS. 
A

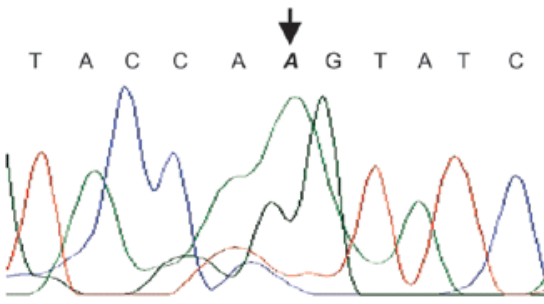

C

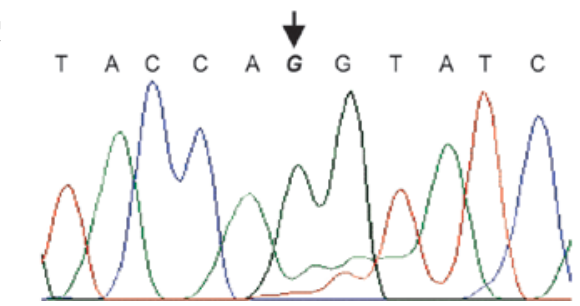

B

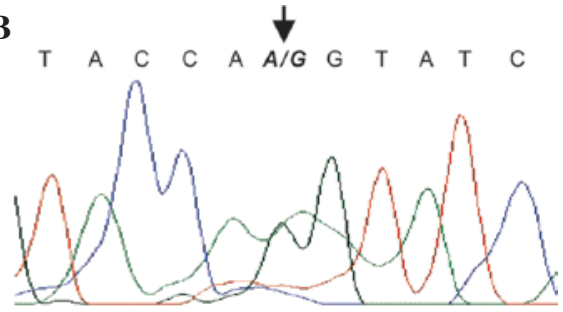

Figure 1. A22G polymorphism was identified by sequencing. Sequencing of the A22G polymorphism was from genomic DNA of 70 individuals with acute lymphoblastic leukemia and 100 healthy individuals without a family history of leukemia. The arrows indicate the nucleotide variants. (A) Homozygote genotype 22A/A, (B) heterozygote genotype 22A/G and (C) homozygote genotype 22G/G.

\section{A}

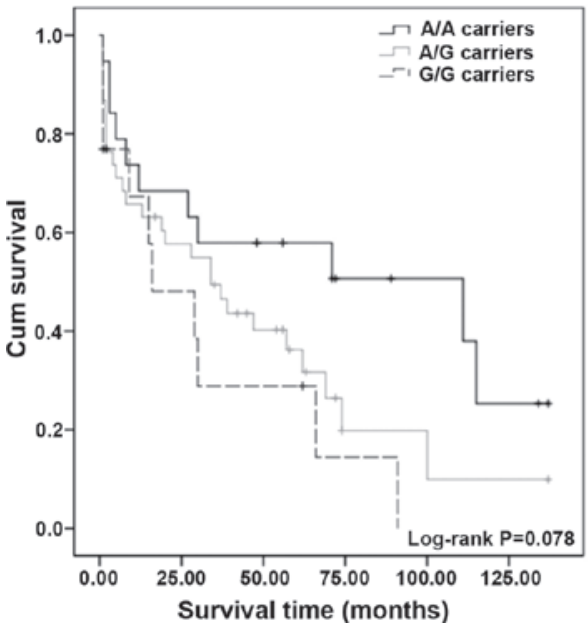

B

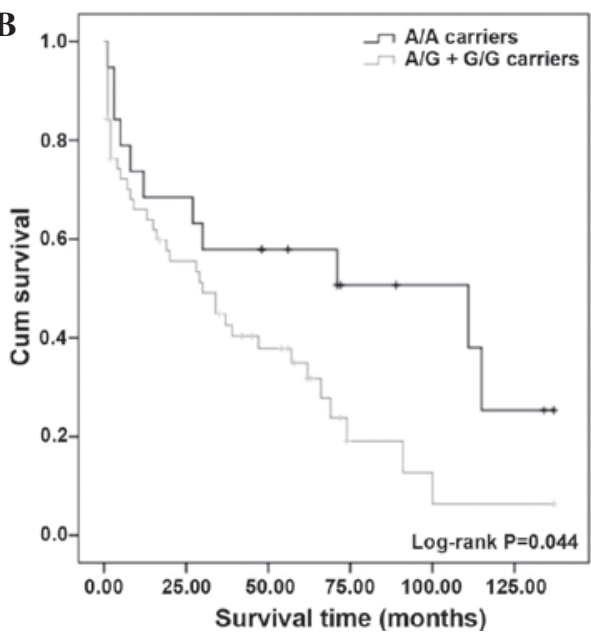

Figure 2. Kaplan-Meier curves of the effects of FPGS A22G polymorphism on overall survival of patients with acute lymphoblastic leukemia. (A) Association between overall survival and FPGS A22G polymorphism and (B) combined genotypes A/G + G/G vs. A/A in 70 children with ALL. Crosses indicate censoring. FPGS, folylpolyglutamate synthase.

Wessels et al (11) and Van der Straaten et al (14), found no significant associations between the A22G polymorphism and MTX responses in patients with rheumatoid arthritis. Thus, whether the $\mathrm{A} 22 \mathrm{G}$ polymorphism affects or presents a risk in specific disease therapy has not been clearly determined. However, our findings show a significant difference $(\mathrm{P}<0.05)$ in the frequency of $\mathrm{A} 22 \mathrm{G}$ genotypes between children with and without relapse. Carriers of the G22G genotypes were more likely to relapse $(\mathrm{OR}=2.42 ; 95 \% \mathrm{CI}: 1.99-11.76 ; \mathrm{P}=0.272)$ compared with those with the AA genotype (Table II), suggesting a role for the $\mathrm{A} 22 \mathrm{G}$ polymorphism in the risk of relapse of ALL. In the multivariate analysis, OR estimates for patients with $22 \mathrm{G} / \mathrm{G}$ genotype retained their significance $(\mathrm{OR}=2.44 ; 95 \%$ CI: 2.40-11.82; $\mathrm{P}=0.017)$ in the presence of other prognostic factors, which also affected ALL outcome (age, WBC and risk classes) (Table II). A second aim of this study was to investigate the effect of the polymorphism on survival. The survival rate of $\mathrm{G}$ allele carriers of the $\mathrm{A} 22 \mathrm{G}$ polymorphism was lower than that of patients carrying the A allele (Fig. 2). During follow-up, a reduction in survival among $G$ allele carriers compared to patients with the wild-type genotype was observed (Fig. 2).

To the best of our knowledge, this study is the first to evaluate the effects of the $\mathrm{A} 22 \mathrm{G}$ polymorphism in patients with ALL. Our data generates a novel hypotheses regarding the role of FPGS A22G polymorphism in the risk and relapse of ALL and its effects on the survival of patients with ALL. Further independent studies are required to clarify whether the associations reported in this study which just escaped statistical significance, presumably due to the limited sample size, can be corroborated. It is of interest to determine the association of FPGS variants with the folate pathway, which plays a role as an important target for anticancer therapeutics. These investigations may result in novel therapeutic regimens to correlate individual genetic variations with response to antifolate therapy and efficacy in patients with unfavorable FPGS genotypes. 


\section{Acknowledgements}

The authors would like to thank the patients and their parents for their collaboration, as well as M.Sc. Monica Virginia Saavedra Herrera, Dra. Ana Betha Rivera Ramirez and to Dr. Marco Antonio Teran Porcayo (during tenure) of the State Cancer Institute 'Arturo Beltran Ortega' for their contribution of biological material and facilitating access to clinical data. This study was supported by the National Council of Science and Technology (CONACYT, Mexico) fellowship awarded to M.Sc. Carlos Alberto Rangel Rodriguez (August, 2009 to July, 2011).

\section{References}

1. Daniel-Cravioto A, Gonzalez-Bonilla CR Mejia-Arangure JM, et al: Genetic rearrangement MLL/AF4 is most frequent in children with acute lymphoblastic leukemias in Mexico City. Leuk Lymphoma 50: 1352-1360, 2009.

2. Mejia-Arangure J, Bonilla M, Lorenzana R, et al: Incidence of leukemias in children from El Salvador and Mexico City between 1996 and 2000: population-based data. BMC Cancer 5: 33, 2005

3. Database of Deaths National Institute of Statistics (INEGI)/Health Secretariat (SSA), Directorate General of Health Information, Mexico. February, 2006. Available at: www.inegi.org.mx/ Accessed April, 2008

4. Leil TA, Endo C, Adjei AA, et al: Identification and characterization of genetic variation in the folylpolyglutamate synthase gene. Cancer Res 67: 8772-8782, 2007.
5. Gómez-Gómez Y, Organista-Nava J, Saavedra-Herrera MV, et al: Survival and risk of relapse of acute lymphoblastic leukemia in a Mexican population is affected by dihydrofolate reductase gene polymorphisms. Exp Ther Med 3: 665-672, 2012.

6. Insurance-Popular: Secretary of Health/Seguro Popular. http://www.seguro-popular.gob.mx/. Accessed May, 2009.

7. Leyva-Vázquez MA, Organista-Nava J, Gómez-Gómez Y, et al: Polymorphism G80A in the reduced folate carrier gene and its relationship to survival and risk of relapse in acute lymphoblastic leukemia. J Investig Med 60: 1064-1067, 2012.

8. Merante F, Raha S, Reed J and Proteau G: The Simultaneous Isolation of RNA and DNA from Tissues and Cultured Cells. Methods Mol Biol 58: 3-9, 1996.

9. Organista-Nava J, Gómez-Gómez Y, Saavedra-Herrera MV, et al: Polymorphisms of the gamma-glutamyl hydrolase gene and risk of relapse to acute lymphoblastic leukemia in Mexico. Leuk Res 34: 728-732, 2010.

10. Dulucq S, St-Onge G, Gagné V, et al: DNA variants in the dihydrofolate reductase gene and outcome in childhood ALL. Blood 111: 3692-3700, 2008.

11. Wessels JA, van der Kooij SM, le Cessie S, et al: A clinical pharmacogenetic model to predict the efficacy of methotrexate monotherapy in recent-onset rheumatoid arthritis. Arthritis Rheum 56: 1765-1775, 2007.

12. Lee KM, Lan Q, Kricker A, et al: One-carbon metabolism gene polymorphisms and risk of non-Hodgkin lymphoma in Australia. Hum Genet 122: 525-533, 2007.

13. Lim U, Wang SS, Hartge P, et al: Gene-nutrient interactions among determinants of folate and one-carbon metabolism on the risk of non-Hodgkin lymphoma: NCI-SEER case-control study. Blood 109: 3050-3059, 2007.

14. van der Straaten RJ, Wessels JA, de Vries-Bouwstra JK, et al: Exploratory analysis of four polymorphisms in human GGH and FPGS genes and their effect in methotrexate-treated rheumatoid arthritis patients. Pharmacogenomics 8: 141-150, 2007. 